\title{
Advanced Emissions Control Development Program
}

\author{
DOE Quarterly Technical Progress Report \#15 \\ Revision 0
}

For the period: July 1 to September 30, 1997

Prepared by:

A. P. Evans

United States Department of Energy:

Ohio Coal Development Office Grant Agreement: McDermott Technology, Inc.:
DE-FC22-94PC94251 -12

CDO/D-922-13

CRD-1310
Amy P. Evans

FAX: 330-829-7283

Phone: 330-829-7452 


\section{Legal Notice/Disclaimer}

This report was prepared by McDermott Technology, Inc. pursuant to a Cooperative Agreement partially funded by the U.S. Department of Energy, and neither McDermott Technology, Inc. nor any of its subcontractors nor the U.S. Department of Energy, nor any person acting on behalf of either:

a) Makes any warranty or representation, express or implied, with respect to the accuracy, completeness, or usefulness of the information contained in this report, or that the use of any information, apparatus, method, or process disclosed in this report may not infringe privately-owned rights; or

b) Assumes any liabilities with respect to the use of, or for damages resulting from the use of, any information, apparatus, method or process disclosed in this report.

Reference herein to any specific commercial product, process, or service by trade name, trademark, manufacturer, or otherwise, does not necessarily constitute or imply its endorsement, recommendation, or favoring by the U.S. Department of Energy. The views and opinions of authors expressed herein do not necessarily state or reflect those of the U.S. Department of Energy. 


\section{Executive Summary}

McDermott Technology, Inc. (MTI) is conducting a five-year project aimed at the development of practical, cost-effective strategies for reducing the emissions of hazardous air pollutants (commonly called air toxics) from coal-fired electric utility plants. The need for air toxic emissions controls may arise as the U. S. Environmental Protection Agency proceeds with implementation of Title III of the Clean Air Act Amendment (CAAA) of 1990. Data generated during the program will provide utilities with the technical and economic information necessary to reliably evaluate various air toxics emissions compliance options such as fuel switching, coal cleaning, and flue gas treatment. The development work is being carried out using the Clean Environment Development Facility (CEDF) wherein air toxics emissions control strategies can be developed under controlled conditions, and with proven predictability to commercial systems. Tests conducted in the CEDF provide high quality, repeatable, comparable data over a wide range of coal properties, operating conditions, and emissions control systems. Development work to date has concentrated on the capture of mercury, other trace metals, fine particulate, and the inorganic species, hydrogen chloride and hydrogen fluoride.

\section{Project Sponsors}

The Advanced Emissions Control Development Program is jointly funded by the United States Department of Energy's Federal Energy Technology Center (DOE), the Ohio Coal Development Office within the Ohio Department of Development (OCDO), and the Babcock \& Wilcox Company - a McDermott company (B\&W).

\section{Background}

Promulgation of air toxics emissions regulations for electric utility plants could dramatically impact utilities burning coal, their industrial and residential customers, and the coal industry. Work during the project will supply the information needed by utilities to respond to potential air toxics regulations in a timely, costeffective, environmentally-sound manner which supports the continued use of the Nation's abundant reserves of coal, such as those in the State of Ohio.

\section{The Clean Air Act Amendment of 1990}

Title III of the CAAA's established a list of 189 hazardous air pollutants and charged the EPA with the responsibility for regulating emissions of these substances into the atmosphere as required to protect public health and the environment. The first phase of compliance is to be based on available technology, and will require many industrial plants to install the "maximum achievable control technology" (MACT). Electric utility plants are exempt from this requirement, however, pending the outcome of several risk assessment and emissions characterization studies. The EPA is scheduled to propose its plan for regulating electric utilities under Title III in the near future.

The EPA has been working with the U. S. Department of Energy (DOE), the Electric Power Research Institute (EPRI), and the Utility Air Regulatory Group (UARG) to characterize air toxics emissions from existing power plants. Both DOE and EPRI have conducted major field testing programs toward this end. 
The results of these emissions characterization studies have been reviewed by the EPA in conjunction with the results of several on-going EPA risk assessment studies to determine the need for air toxics emissions regulations aimed at electric utilities. These field testing programs provide considerable insight into the quantities of air toxics being emitted by power plants. However, MTI believes that they are only a first step toward developing an understanding of the formation, partitioning, and capture of air toxics species, and how to effectively control their emissions.

While the EPA's ultimate approach is uncertain, at least some air toxics species issuing from utility stacks may be regulated - especially some of the high-risk compounds such as arsenic, cadmium, chromium, and mercury, and/or compounds known to be emitted in relatively large quantities such as hydrogen chloride and hydrogen fluoride. Mercury, in particular, is the subject of intensive research due to its presence in the atmosphere, subsequent deposition in lakes, and potential human health and environmental impacts. MTI strongly believes that a proactive approach to the development of the technical and economic information utilities will need to assess air toxics control options is needed to keep pace with regulatory actions.

\section{Overview of the Project}

The objective of this project is to develop practical strategies and systems for the simultaneous control of $\mathrm{SO}_{2}, \mathrm{NO}_{x^{\prime}}$ particulate matter, and air toxics emissions from coal-fired boilers in such a way as to keep coal economically and environmentally competitive as a utility boiler fuel. Of particular interest is the control of air toxics emissions through the cost-effective use of conventional flue gas clean-up equipment such as electrostatic precipitators (ESP's), fabric filters (baghouses), and $\mathrm{SO}_{2}$ removal systems such as wet scrubbers and various "clean coal technologies". This objective will be achieved through extensive development testing in the state-of-the art, $10 \mathrm{MW}_{\mathrm{e}}$ equivalent, Clean Environment Development Facility. The project has extended the capabilities of the CEDF to facilitate air toxics emissions control development work on "backend" flue gas cleanup equipment. Specifically, an ESP, a baghouse, and a wet scrubber for $\mathrm{SO}_{2}$ (and air toxics) control were added -- all designed to yield air toxics emissions data under controlled conditions, and with proven predictability to commercial systems. A schematic of the CEDF and the project test equipment is shown in Figure 1.

The specific objectives of the project are to:

Measure and understand production and partitioning of air toxics species in coal-fired power plant systems.

Optimize the air toxics removal performance of conventional flue gas cleanup systems.

Quantify the impacts of coal cleaning on air toxics emissions.

Identify and/or develop advanced air toxics emissions control concepts.

Develop and validate air toxics emissions measurement and monitoring techniques.

Establish an air toxics data library to facilitate studies of the impacts of coal selection, coal cleaning, and emissions control strategies on the emissions of coal-fired power plants. 


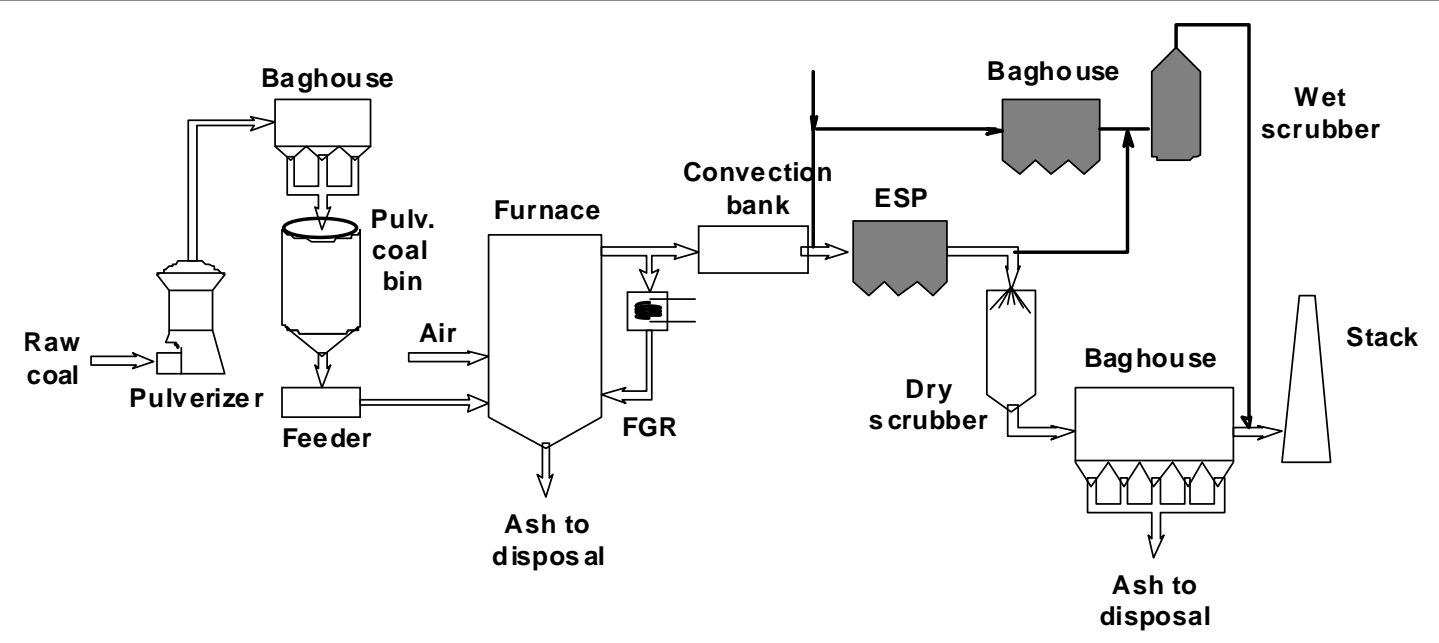

$\square$ B\&W CE DF

Full flow stream

$\square$ AECDP Test Equipment

Figure 1 -- Clean Environment Development Facility

\section{Description of Project Phases}

The project is divided into three phases. Phase I (Facility Modification and Benchmarking) consisted of installation, shakedown, validation, and benchmarking of the test equipment added to the CEDF. Baseline air toxics emissions and capture efficiency were established for each of the major flue gas cleanup devices: ESP, baghouse, and wet $\mathrm{SO}_{2}$ scrubber. All tests were conducted with a high sulfur, Ohio steam coal. The work in this phase culminated in the development of a data library, or database, for use by project participants.

Phase II (Optimization of Conventional Systems) testing involved the development of air toxics control strategies based on conventional flue gas cleanup equipment. Work in this area was directed at the optimization of mercury, acid gas and fine particulate capture in conventional particulate and $\mathrm{SO}_{2}$ control equipment. Baseline emissions and capture of air toxics were established for each of the major cleanup devices: ESP, baghouse, and wet $\mathrm{SO}_{2}$ scrubber. Phase II testing provided data on the impacts of coal properties on mercury and acid gas emissions for several steam coals. The impacts of coal cleaning on air toxics emissions was investigated through the testing of two high production coals processed at commercial wash plants and chemical analysis of the associated parent (uncleaned) coals. Two developmental mercury emissions monitors were also investigated in this phase.

Phase III (Advanced Concepts and Comparison Coals) testing will be directed at the development of new air toxics emissions control strategies and devices, to further reduce the emissions of selected toxics. Testing will also be conducted to extend the air toxics data library to include a broader range of coal types. Finally, the development work on advanced air toxics emissions measurement and monitoring techniques begun in Phase II will continue in Phase III. 


\section{Summary of Phase I Results}

Phase I -- Facility Modifications and Benchmarking -- work began on November 1, 1993, and ended on February 29, 1996. Phase I activities were primarily directed at providing a reliable, representative test facility for conducting air toxic emissions control development work later in the project. The AECDP equipment installed on the CEDF consisted of an ESP, fabric filter, and wet scrubber. All verification and air toxic tests were conducted with an Ohio high sulfur, bituminous coal.

\section{Fabric Filter}

The fabric filter system (Figure 2) comprises a pulse-jet baghouse and fly ash disposal system. The fabric filter is designed for a partial flow flue gas slipstream from the CEDF of approximately $0.6 \mathrm{MW}_{\mathrm{e}}$ equivalent.

Pulse-Jet Baghouse. Particulate from the flue gas stream is collected on the outside surface of porous filter bags in the baghouse. The pulse-jet baghouse is named for the manner in which the bags are cleaned. The filter cake is removed from the outer surface of the bag by a pulsed jet of compressed air supplied to its interior which causes a sudden bag expansion. The dust is effectively removed by inertial forces as the bag reaches maximum expansion. The baghouse was initially configured with commercial size, conventional fabric filter bags to simulate air toxics capture in commercial baghouses. The baghouse design permits operation over a wide range of air-to-cloth ratio (a measure of the amount gas passing through each square foot of fabric in the baghouse), particulate loading, cleaning cycle frequency and cleaning pressure. The baghouse temperature can be varied to evaluate the effect of operating temperature on air toxics and particulate collection. Particulate collection efficiency can also be affected by the type of fuel combusted, the resulting particulate characteristics, and the particle size distribution.

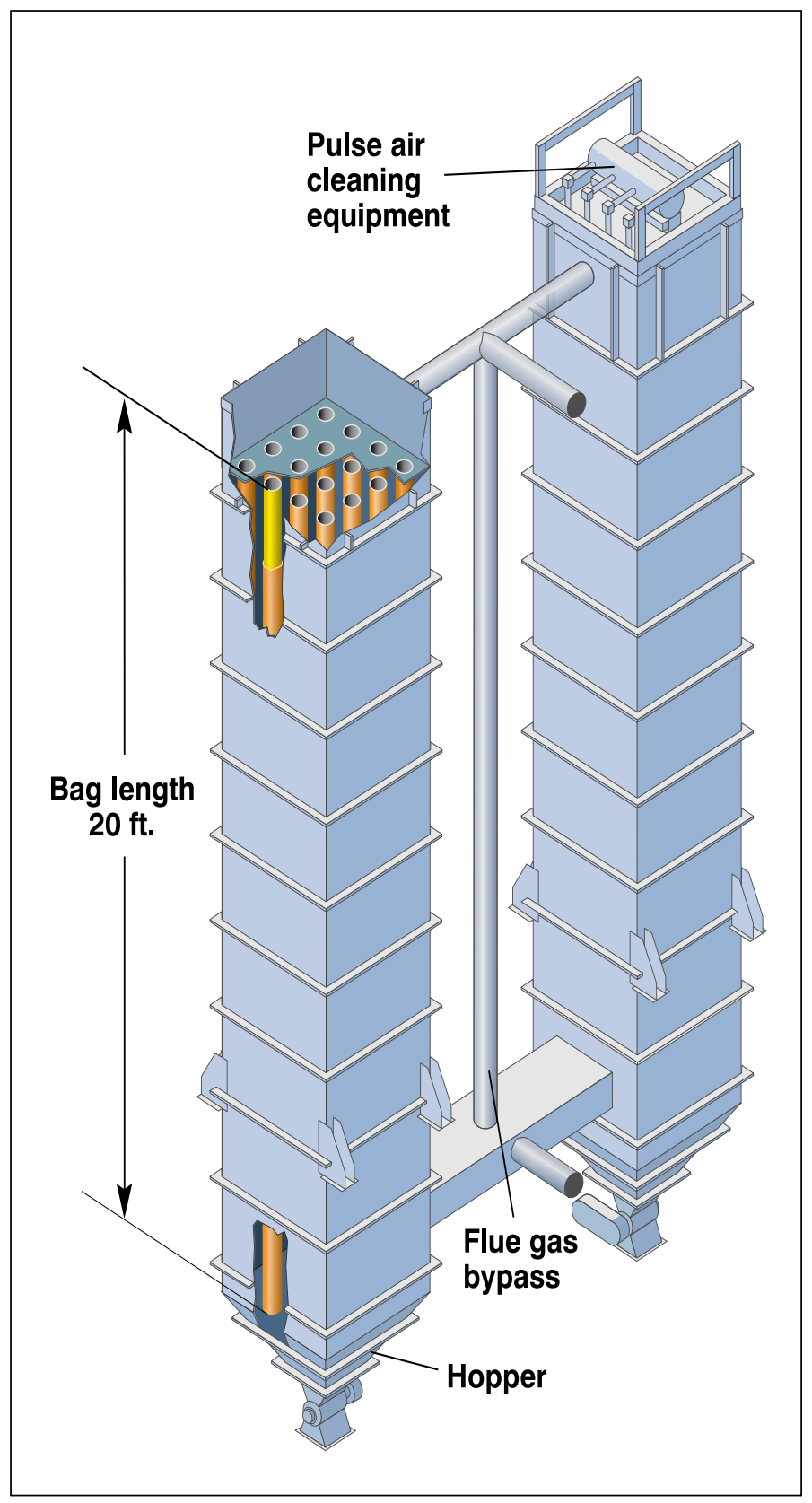

Figure 2 -- Pulse-Jet Baghouse 
The baghouse is designed to process $6,000 \mathrm{lb} / \mathrm{hr}$ of flue gas with a particulate loading of $94 \mathrm{lb} / \mathrm{hr}$. The baghouse will reduce particulate emissions to less than the New Source Performance Standard of $0.03 \mathrm{lb} / 10^{6} \mathrm{Btu}$. The primary design characteristics for the baghouse are summarized below:

\section{AECDP Baghouse Design Summary}

\author{
Compartments \\ Bags/Compartment \\ Bag dimensions \\ Air-to-Cloth ratio \\ Cleaning method
}

\author{
two; $33 \mathrm{ft}$ high $\times 4 \mathrm{ft}$ square \\ 16 \\ $61 / 4$ inch diameter $\times 20 \mathrm{ft}$ long \\ 3.2 to $5.2 \mathrm{ft} / \mathrm{sec}$ \\ Pulse-jet; on-line or off-line
}

\section{Wet Scrubber}

The 0.6 MW $\mathrm{MW}_{\mathrm{e}}$ equivalent wet scrubber subsystems include the absorber tower, reagent feed system, mist eliminator system, and slurry dewatering and disposal system. The absorber tower (Figure 3) is designed to simulate a vertical section down through a commercial reactor to accurately reproduce $\mathrm{SO}_{2}$ and air toxics removal mechanisms. Emphasis is placed on the duplication of gas/liquid interaction, minimization of wall impingement, and the proper simulation of operating parameters that affect particulate control in a wet scrubber. The wet scrubber is designed to treat the flue gas from the partial flow, pulse-jet baghouse or a flue gas slipstream from the full-flow electrostatic precipitator, and includes the equipment required to handle the associated reagent and waste streams.

Absorber. The absorber consists of the absorber tower and slurry recirculation tank. The particulate loading in the flue gas entering the absorber tower depends upon the operating efficiency of either the upstream ESP or pulse-jet baghouse, and is typically around $0.03 \mathrm{lb} / 10^{6} \mathrm{Btu}$. The absorber tower operating conditions are influenced by the type of fuel. The design is based on B\&W's commercial scrubbers and incorporates a perforated-plate tray to reduce flue gas flow maldistribution. The absorber tower comprises several interchangeable modules to vary the number of perforated trays and the tray height. The modular tower design permits testing with different spray and tray configurations to best simulate the operation of conventional wet scrubbers.

The wet scrubber is designed to process $5,062 \mathrm{lb} / \mathrm{hr}$ of flue gas with a $\mathrm{SO}_{2}$ concentration of up to 6,000 $\mathrm{ppm}$. The primary design characteristics for the wet scrubber system are summarized in the following table:

\section{AECDP Wet Scrubber Design Summary}

\author{
Design limestone stoichiometry \\ Nominal $\mathrm{SO}_{2}$ removal \\ Design $\mathrm{L} / \mathrm{G}$ ratio \\ Normal L/G ratio \\ Tower velocity range
}

1.1 mole $\mathrm{Ca} /$ mole $\mathrm{SO}_{2}$ absorbed $90 \%$

$267 \mathrm{gpm} / 1000 \mathrm{acfm}$

$120 \mathrm{gpm} / 1000 \mathrm{acfm}$

5.0 to $20 \mathrm{ft} / \mathrm{sec}$ 
Absorber Recirculation Tank. The absorber recirculation tank is located below the absorber tower to facilitate the gravimetric flow of reaction products into the tank. The design of the recirculation tank facilitates the evaluation of the degree of forced oxidation on $\mathrm{SO}_{2}$ removal and air toxics collection in the wet scrubber. The air sparger system provides clean, humidified air to obtain a wide range of oxidation levels. The absorber recirculation tank is equipped with an agitator to keep the solids from settling. The $\mathrm{pH}$ of the slurry stream from the recirculation tank to the spray nozzles is monitored with an inline $\mathrm{pH}$ sensor. The continuous $\mathrm{pH}$ measurement is used to control the slurry feed rate from the fresh slurry storage tank to the recirculation tank.

Reagent Feed System. This system comprises a slurry storage/preparation tank, agitator, and pump and operates in a batch mode. The reagent (typically limestone) preparation system does not include a ball mill for grinding the limestone on site. Pulverized limestone is delivered to the facility. The reagent feed system is designed to handle a wide range of slurry feed rates and reagents to achieve specific levels of $\mathrm{SO}_{2}$ control for the variety of coals.

Mist Eliminator System. Mist eliminators minimize carryover of slurry and liquid droplets generated in the absorber tower. To prevent buildup and plugging, the mist eliminators are periodically washed by way of water spray nozzles. The wet scrubber is designed to operate with vertical flow and/or horizontal flow mist eliminators. The system also includes a mist eliminator wash/recycle tank. To evaluate the impacts of mist eliminator efficiency on particulate collection efficiency and air toxics capture, sampling ports are located at the inlet and outlet of the mist eliminator sections. The modular tower design permits simple removal of the mist eliminator sections for testing purposes.

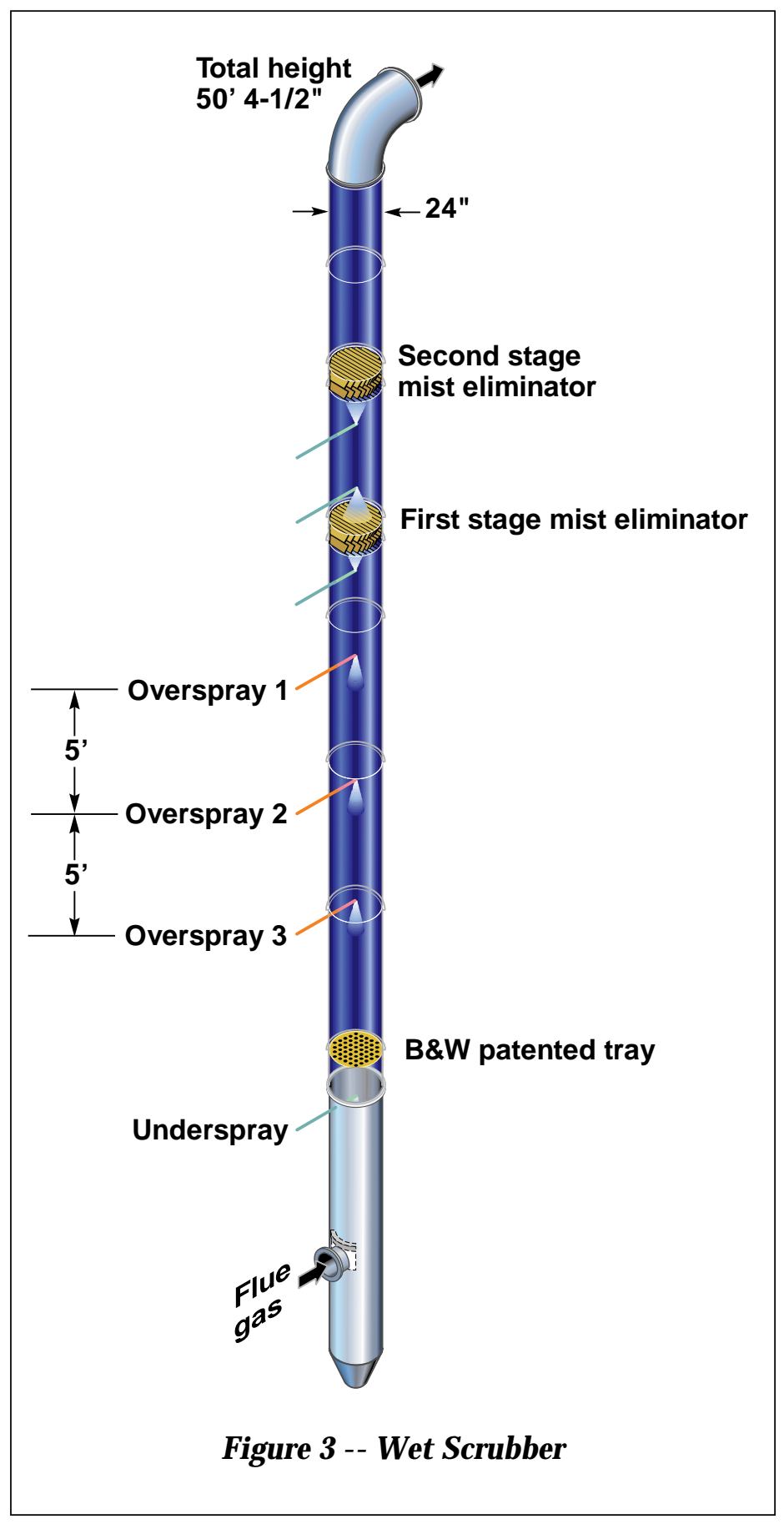




\section{Electrostatic Precipitator}

The ESP (Figure 4) operates on the full flue gas flow (100 million Btu/hr, $10 \mathrm{MW}_{\mathrm{e}}$ equivalent) from the CEDF. The ESP was supplied by B\&W's commercial Environmental Equipment Division (EED). Design of the ESP follows conventional practice used commercially in power boiler emissions control. The ESP consists of discharge electrodes which impart an electric charge to ash particles in the flue gas as it passes through the ESP. The charged particles are attracted to charged collector plates and are removed from the gas stream. The plates are rapped periodically to remove the collected particles. The ash falls into hoppers below the plates and is removed from the ESP through rotary air locks.

The ESP design is sufficiently flexible to treat flue gas from a range of coals with variable ash and sulfur contents. The ESP is designed to process $102,893 \mathrm{lb} / \mathrm{hr}$ of flue gas with a particulate loading of $1883 \mathrm{lb} / \mathrm{hr}$. The ESP is designed to reduce particulate emissions to less than the New Source Performance Standard of $0.03 \mathrm{lb} / 10^{6} \mathrm{Btu}$. The ESP includes wire discharge frames and rigid discharge electrodes. Both discharge systems are used in commercial ESPs. The primary design characteristics for the ESP are summarized in the following table:

\section{AECDP ESP Design Summary}

\author{
Electric fields \\ Specific collection area (SCA) \\ Flue gas velocity \\ Migration velocity \\ Residence time \\ Transformer rectifier sets
}

\author{
four; $6 \mathrm{~m}$ high $\mathrm{x} 4 \mathrm{~m}$ deep \\ $330-370 \mathrm{ft}^{2} / 1000$ ACFM \\ 3.6 to $4.0 \mathrm{ft} / \mathrm{sec}$ \\ 7.5 to $9.8 \mathrm{~cm} / \mathrm{sec}$ \\ 13 to $14 \mathrm{sec}$ \\ four; $75 \mathrm{kV}, 125 \mathrm{~mA}$
}

\section{Verification Testing}

In addition to facility design and construction, completed tasks in Phase I also included equipment verification, air toxics benchmarking and the establishment of a database. During the verification process, the test facility operation was compared with commercial systems in order to apply the program results to utility systems. The CEDF was numerically modeled to yield combustion zone temperatures, flow patterns, and residence times representative of commercial boilers. Careful control of the flue gas cooling rate through the boiler convection pass and air heater simulators provides a gas time-temperature profile that is similar to commercial units to generate similar levels and forms of trace substances. Measurements performed in Phase I confirmed that representative gas phase timetemperature profiles and surface metal temperatures are maintained throughout the furnace and convection pass while firing a bituminous coal. 


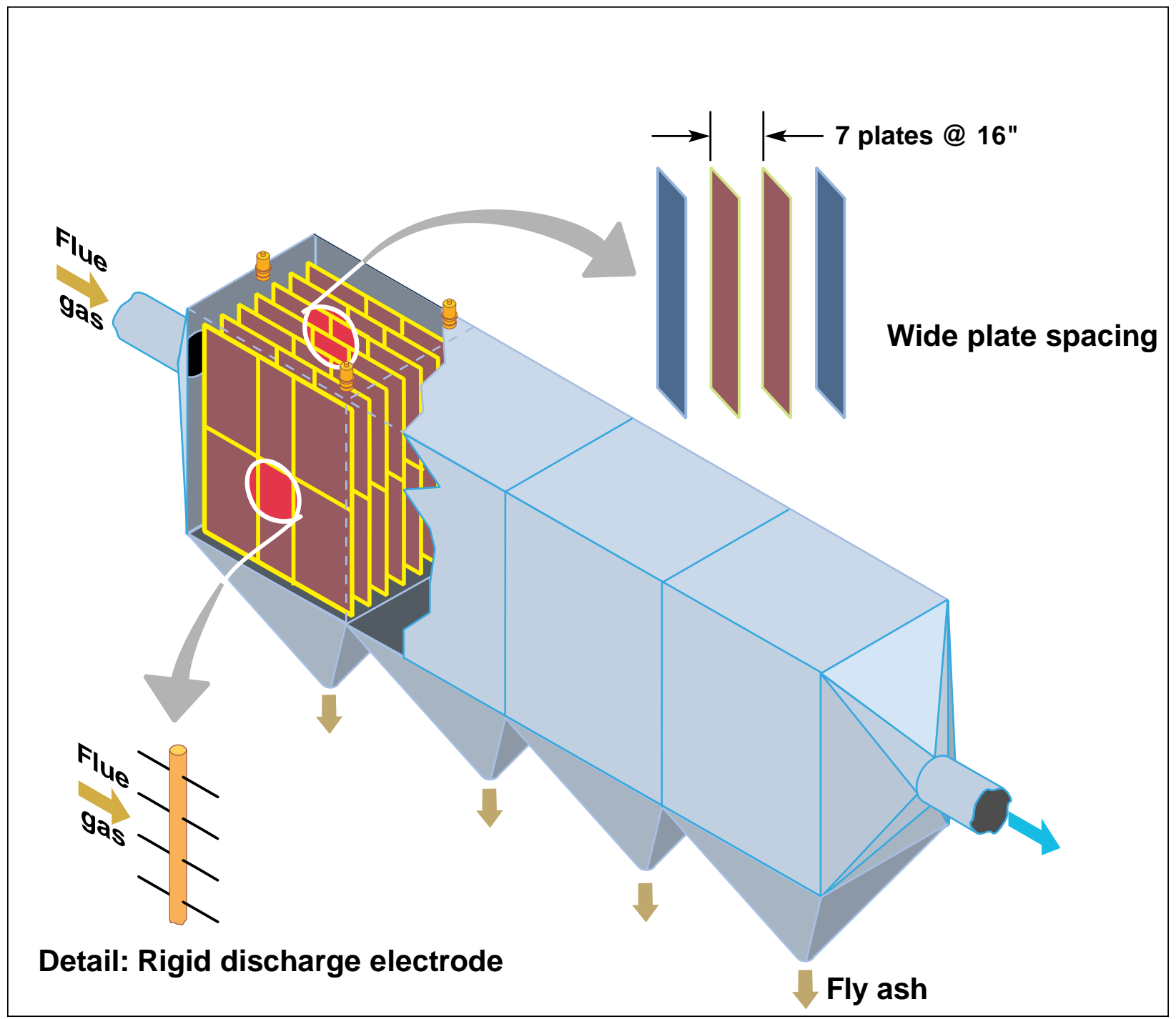

Figure 4 -- Electrostatic Precipitator

Although the flue gas and tube metal temperature measurements conducted in the CEDF furnace and convection pass suggested that the air toxics generated by the CEDF should be representative of field emissions, air toxic benchmarking measurements were also performed to quantify the air toxics emissions from the boiler and the back-end equipment. Air toxic emission verification was achieved through comparison of the air toxics measured from the CEDF with the emissions predicted by the trace element content in the coal and the draft emission modification factors (EMF) established by the EPA. The similarity between the predicted and measured emissions, as shown in Figure 5, indicate that the trace metals emitted from the CEDF are representative of commercial units firing bituminous coal. 


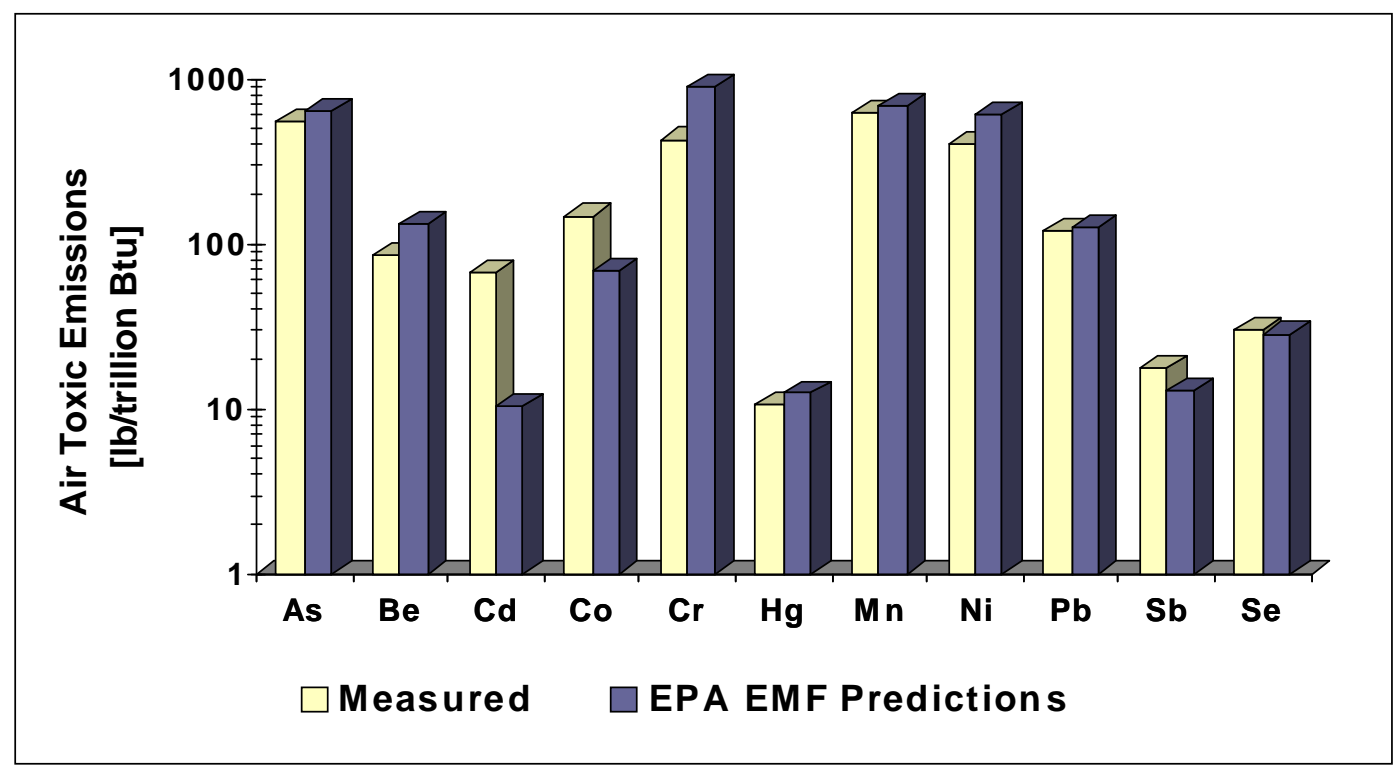

Figure 5 -- Representative Trace Metal Emissions from CEDF Boiler 


\section{Summary of Phase II Results}

Phase II -- Optimization of Conventional Systems -- work began on February 29, 1996, and ended on August 31, 1997. The first two tests of Phase II were directed at the development of air toxics control strategies, based on conventional particulate and $\mathrm{SO}_{2}$ control equipment. The initial test series focused on mercury speciation, particulate and vapor-phase trace metal emissions and fine particulate emissions. Emphasis was placed on characterization of ESP and baghouse trace element emissions control performance. The control of mercury emissions with a wet limestone scrubber was broadly characterized during the second test series at conditions representative of a range of commercial scrubber operation. The third test series provided data on the impacts of coal properties on mercury emissions for several Ohio steam coals. The impact of coal cleaning on mercury emissions was investigated through the testing of commercially cleaned coals and their associated parent (uncleaned) coals. Two advanced measurement systems, a mercury monitor and a Fourier Transform Infrared Spectrometry analyzer (FTIR), were also evaluated in this phase.

\section{Sampling and Analytical Procedures}

An accurate measure of the mercury species (elemental and oxidized) is essential to the development of mercury control options since the forms impact the performance of emissions control equipment. EPA Method 29 was selected as the EPA-approved grab sampling method for total mercury and to provide consistency with the Phase I efforts. The Ontario Hydro method, which has been evaluated by several organizations to provide an improved measure of the elemental and oxidized mercury species relative to EPA Method 29, was most frequently employed. Improvements were made in the developmental Ontario Hydro method to accurately measure mercury in coal-fired flue gas. Initially, total mercury emissions as measured by EPA Method 29 were higher than measured with the Ontario Hydro method. The lower mercury levels measured by the Ontario Hydro method were primarily related to the selection of a preservative intended to retard loss of mercury during the analytical recovery of the sample trains. Permanganate was then selected as the preservative on the basis of the visual color change and stronger oxidizing properties than the previous dichromate preservative. The use of the permanganate preservative during the second and third test series resulted in improved agreement in the measure of total mercury emissions between the two methods. Total mercury emissions from the CEDF boiler as measured by Method 29 and Ontario Hydro are compared in Figure 6.

\section{Particulate Control Devices}

The potential for improved control of particulate metal emissions was investigated. Of the particulate metals, arsenic, cadmium, chromium, lead, manganese and nickel have been specified in the interim final USEPA report, Study of Hazardous Air Pollutant Emissions from Electric Utility Steam Generating Units, as potential health risks. Operating temperature, flue gas humidification, and baghouse fabric were evaluated as cost-effective means of reducing particulate and trace metal emissions.

The partitioning of metals between the vapor and particulate phases was measured while firing a blend of Ohio 5 and 6 coals. The comparable results from Phase I and Phase II demonstrated the 


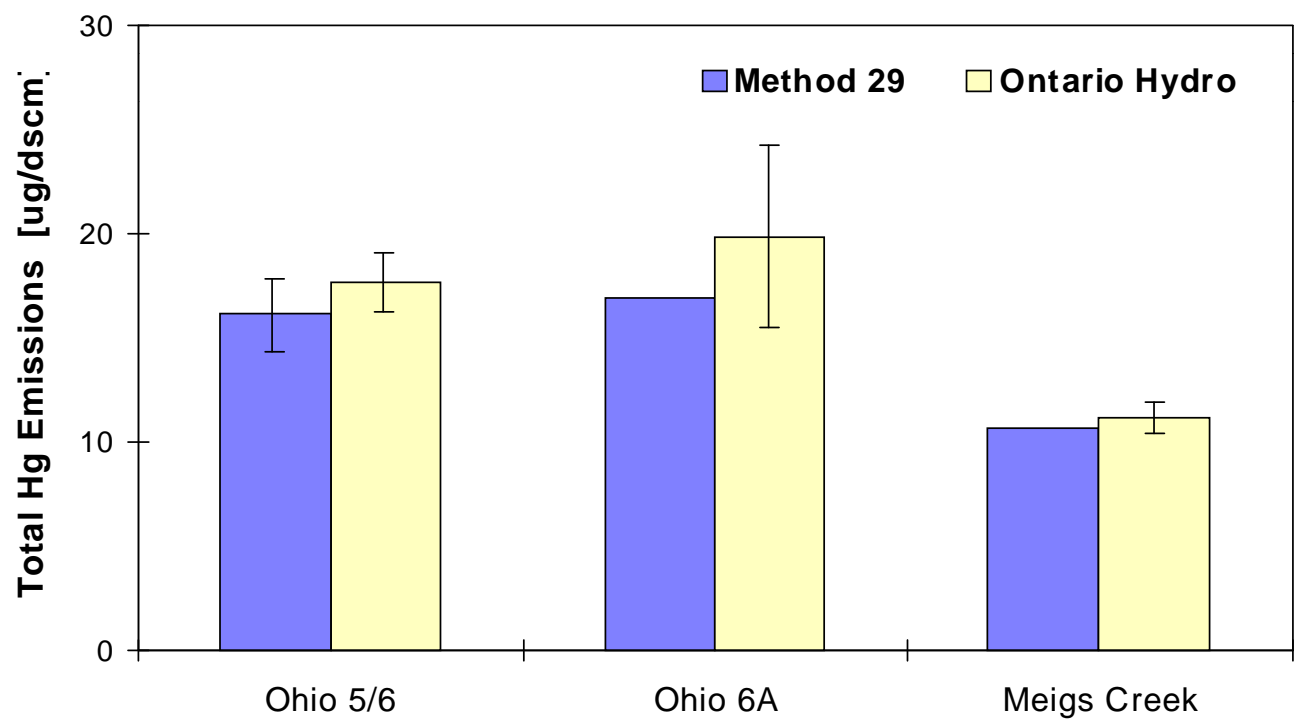

Figure 6 -- Comparison of Total Uncontrolled Mercury Emissions According to EPA Method 29 and Ontario Hydro

reproducibility of CEDF operation with regard to trace metal emissions. Particulate partitioning greater than $99 \%$ was consistently measured for the trace metals with the exception of cadmium, selenium, and mercury. Total emissions control exceeded $97 \%$ for the pulse-jet baghouse and $95 \%$ for the ESP for many of the trace metals. The exceptions were arsenic, cadmium, selenium, and mercury. The higher level of particulate metal control achieved by the baghouse can be attributed to the lower particulate emissions from the baghouse compared to the ESP.

Arsenic, cadmium, chromium, selenium, and mercury were selected for further study on the basis of their perceived health risk, volatility, and potential for improvements in emissions control. Evaluated methods of reducing trace metal and particulate emissions from the particulate control devices included changes in operating temperature, ESP electrical conditions, and baghouse fabric. Highlights from these tests include:

Reduction of particulate emissions by the ESP resulted directly in reduced arsenic and chromium emissions but did not measurably influence total cadmium and selenium emissions.

Humidification was evaluated as a method of decreasing total ESP particulate and metals emissions. However, at the high level of particulate control $(<0.01 \mathrm{lb} /$ million Btu) achieved prior to humidification, flue gas humidification was not observed to have a significant effect on particulate or particulate-bound metals emissions. ESP humidification provided a modest reduction in the gas-phase chromium emissions.

Particulate-phase emissions of arsenic, cadmium, and selenium downstream of the GORETEX® fabric were significantly lower than for the more conventional Ryton fabric. The average arsenic, cadmium, and selenium emissions were between 56 to $69 \%$ lower downstream of the GORE-TEX® fabric relative to the Ryton fabric. The improvement in metals control by the GORE-TEX $®$ fabric directly correlated to an average $58 \%$ reduction in particulate emissions. 
Further reductions of the particulate and particulate-phase metals were achieved with the wet scrubber. Particulate emissions were reduced by approximately $30 \%$ across the scrubber leading to reductions in particulate-phase arsenic, chromium and cadmium emissions.

In anticipation of fine particulate (PM2.5) regulations, particle size distribution measurements were conducted to characterize particulate and unburned carbon emissions from a low $\mathrm{NO}_{\mathrm{x}}$ burner. Field studies performed on commercial boilers have shown that low $\mathrm{NO}_{x}$ burners tend to produce fly ashes that are finer and which have a lower bulk density than fly ashes produced from turbulent burners. Analysis of the material collected on the individual stages of a cyclone impactor suggest that the majority of the fine particulate ( $<2.5$ microns) emitted by the CEDF low $\mathrm{NO}_{x}$ burner was less than 0.5 micron and that nearly half the unburned carbon was substantially sub-micron. This submicron material (or soot) may not be well controlled by an electrostatic precipitator due to the size and conductivity of the material.

Total baghouse mercury control varied from 0 to $16 \%$ for three different Ohio bituminous coals (Ohio 5/6, Ohio 6A, Meigs Creek). The majority of the mercury removal can be attributed to the mercury adsorbed onto the particulate entering the baghouse. The role of unburned carbon on the amount of mercury on the particulate and, therefore, also on the mercury removal achieved by the particulate control device is uncertain. The impact of baghouse temperature on mercury emissions was examined over the baghouse temperature range of $280-350{ }^{\circ} \mathrm{F}$ for the baseline Ohio $5 / 6$ coal. Temperature reduction did not alter total mercury emissions although reduced baghouse temperature did favor the transformation of elemental mercury across the baghouse.

The primary contribution of a conventionally operated baghouse toward the removal of vapor-phase mercury emissions from a scrubbed utility power plant appears to be the conversion of elemental mercury by the fly ash filter cake. The proportion of the mercury species from the boiler was fairly consistent for the four Ohio bituminous coals characterized. On average, 18\% of the uncontrolled vapor-phase mercury was measured in the elemental form as illustrated in Figure 7. However, once the flue gas passed through the baghouse, the proportion of elemental mercury was reduced. In light of literature reports that baghouse fabric impacts mercury speciation, two different baghouse fabrics (Ryton and GORE-TEX®) were evaluated. The elemental mercury emissions measured at the baghouse outlet were comparable between fabrics, suggesting that the mercury transformation was primarily due to the bituminous coal fly ash. Increased levels of oxidized mercury corresponding to the oxidation of elemental mercury were periodically measured during Ohio 5/6 baghouse tests and consistently measured during subsequent Ohio 6A and Meigs Creek baghouse tests. The extent of oxidation of elemental mercury was consistent for each of the Ohio bituminous coal fly ashes. The average baghouse outlet elemental mercury concentration was $46 \%$ lower than the inlet for the Ohio $6 \mathrm{~A}$ coal, $72 \%$ lower for the Meigs Creek coal and $65-70 \%$ lower for the Ohio 5/6 coal at a baghouse temperature of $310^{\circ} \mathrm{F}$. As a result, a baghouse/wet scrubber system has a high potential for total mercury emissions reduction due to the conversion of elemental mercury to a more soluble form. This was substantiated during Ohio 6A and Meigs Creek tests when significantly higher mercury control was obtained by the wet scrubber preceded by a baghouse when directly compared to an ESP/wet scrubber configuration. 


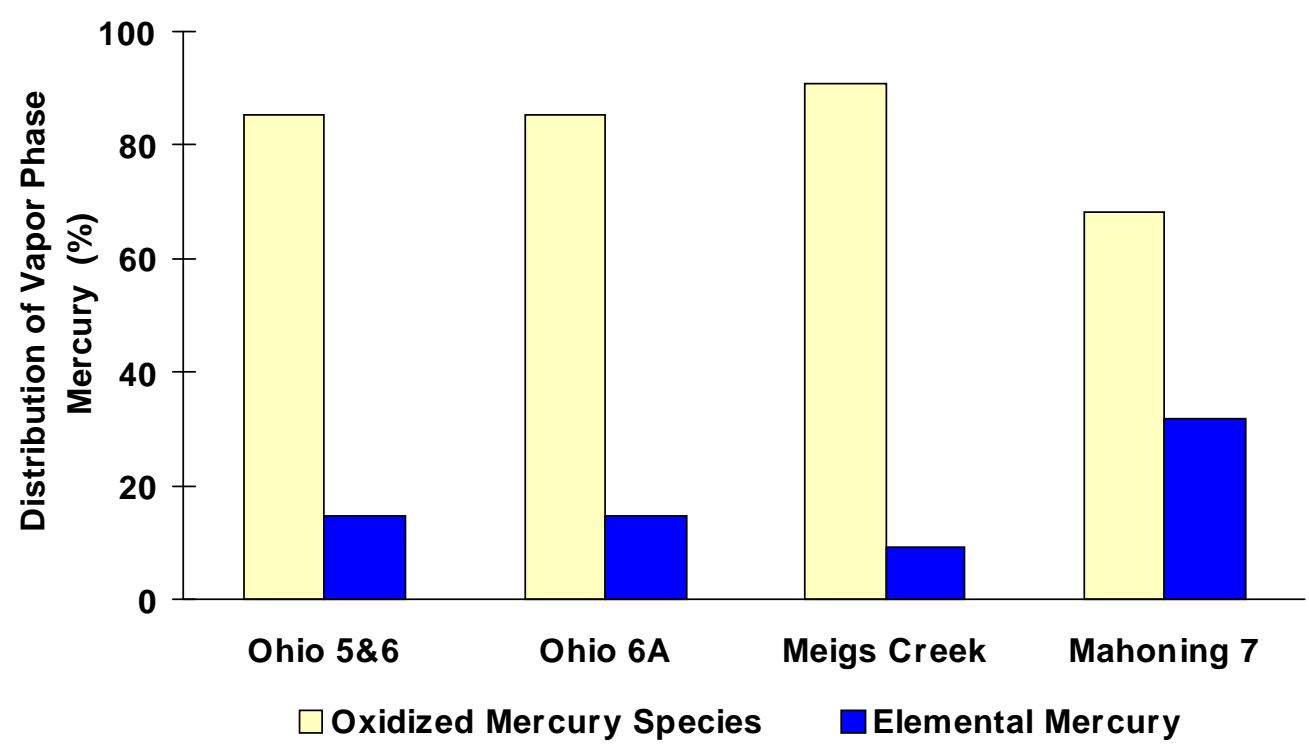

Figure 7 -- Characterization of Uncontrolled Mercury Emissions for Ohio Bituminous Coals

However, ESPs are the dominant particulate emissions control system installed at U.S. commercial coal-fired generating plants. The AECDP pilot test data suggests that ESPs can remove a significant portion of the particulate-phase mercury but have a limited effect on vapor-phase mercury. In contrast to the baghouse, the ESP had no measurable impact on the elemental mercury concentration for the three Ohio coals tested. Modifications to the flue gas temperature over the range of $250-300{ }^{\circ} \mathrm{F}$ had no impact on elemental mercury emissions from the ESP for the baseline Ohio 5/6 coal.

\section{Flue Gas Desulfurization Devices}

Wet scrubber mercury emissions control data reported in the literature and cited by EPA as the basis for evaluating emissions from existing systems represents a relatively narrow range of scrubber design and operating conditions. The USEPA report, Study of Hazardous Air Pollutant Emissions from Electric Utility Steam Generating Units - Interim Final Report, notably estimated a median mercury emissions control efficiency of $17 \%$ for wet scrubbers with a range of 0 to $59 \%$ on the basis of sampling at five commercial plants. Underestimating mercury removal in the existing population of FGD systems and the potential for additional mercury emissions reductions in new FGD installations may result in an over-estimation of U.S. utility mercury stack emissions. Mercury emissions control was characterized for a wet limestone scrubber over a range of conditions representative of commercial scrubber design and operation. Key wet scrubber design and operating parameters included tray configuration, oxidation mode, liquid-to-gas ratio $(\mathrm{L} / \mathrm{G})$ and slurry $\mathrm{pH}$. Evaluation of the four selected variables was intended to expand the characterization of mercury control of limestone scrubbers operating on bituminous coalfired generating units in the U.S.

Total mercury control achieved by the wet scrubber was variable over a wide range of scrubber operating conditions, tower configurations and coal type. Control of oxidized mercury was generally greater than $80 \%$, despite the changes in operating condition, tower configuration, and coal type. 
Elemental mercury, which may account for up to $25 \%$ of the mercury generated by bituminous coal combustion, was not well controlled by the wet scrubber.

Total mercury emissions control across the scrubber for the same coal was influenced by whether the ESP or baghouse was used for upstream particulate emissions control. This effect is shown in Figure 8 for a single wet scrubber operating condition. Consistently high mercury control (provided in the parenthesis) was achieved by the baghouse/wet scrubber system when the scrubber was configured for high $\mathrm{SO}_{2}$ removal. An apparent contribution towards the difference in mercury control is the higher fraction of oxidized mercury in the flue gas from the baghouse compared to the ESP. A second contribution to the difference in total mercury control was the measurable increase in elemental mercury emissions across the scrubber when operated after the ESP.

Extensive parametric testing was performed with the baghouse/wet scrubber system with the baseline Ohio 5/6 coal. Mercury control improved with increased L/G for both an open and tray tower configuration over a range of slurry $\mathrm{pH}$. Emissions of oxidized mercury were reduced as the $\mathrm{L} / \mathrm{G}$ was increased. The slurry $\mathrm{pH}$ did not have a significant impact on oxidized mercury emissions. Elemental mercury emissions from the wet scrubber were fairly constant over the wide L/G range investigated. A gas flow distribution tray in the wet scrubber enhanced both $\mathrm{SO}_{2}$ and total mercury emissions control over a wide range of $\mathrm{L} / \mathrm{G}$ and $\mathrm{pH}$. The enhancement of $\mathrm{SO}_{2}$ and total mercury control by the tray was pronounced at low $\mathrm{L} / \mathrm{G}$ operating conditions. The major contribution towards the lower mercury emissions was the improved removal of soluble oxidized mercury emissions when the tray was installed. Elemental mercury emissions were generally unaffected by the tray configuration. In addition, $\mathrm{SO}_{2}$ and mercury emissions from the tray tower were less variable than from the open tower at similar operating conditions. The better consistency in $\mathrm{SO}_{2}$ and mercury emissions with the tray tower configuration relative to the open tower may be due to the reduction of flue gas channeling.

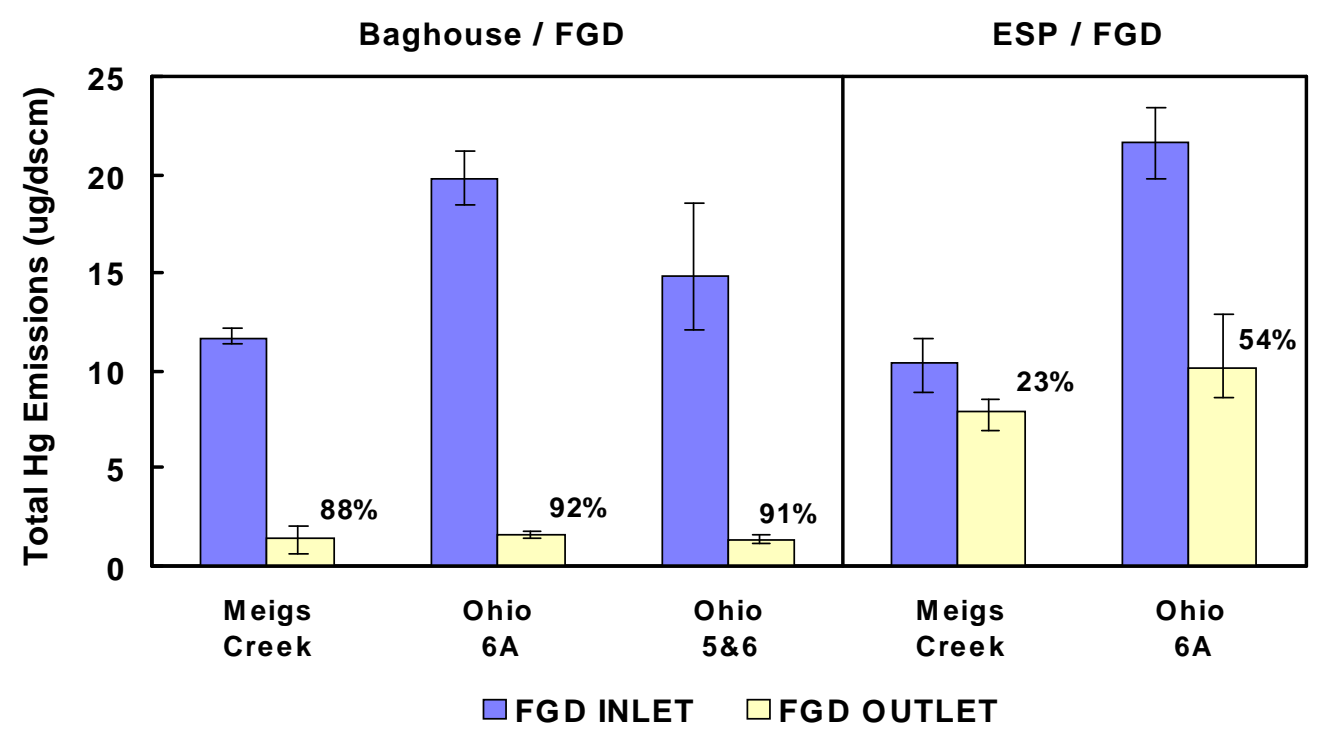

Figure 8 -- Summary of Wet Scrubber Total Mercury Control 
Total mercury control was not measurably affected by a switch from forced to natural oxidation for limited tests performed at high L/G test conditions. However, during the tests in which the wet scrubber was configured in the "natural oxidation" mode, elemental mercury emissions were consistently lower than when the scrubber was operated in the "forced oxidation" mode.

The relationship between wet scrubber $\mathrm{SO}_{2}$ removal efficiency and mercury emissions control was examined. Parametric tests with a single coal evaluated the impact of wet scrubber operating conditions on both mercury and $\mathrm{SO}_{2}$ control. Wet scrubber operating conditions that provided for low $\mathrm{SO}_{2}$ control efficiency tended to also result in low mercury control for the bituminous coal-fired flue gas. Changes in wet scrubber operation to enhance $\mathrm{SO}_{2}$ control such as the installation of a tray or an increase in L/G improved mercury control.

During the wet scrubber parametric tests, the scrubber by-products were analyzed to determine the fate of the controlled mercury emissions. The majority of the mercury captured in the wet scrubber typically ended up in the solid phase of the scrubber discharge during scrubber operation that provided for high $\mathrm{SO}_{2}$ emission control. Extremely low quantities of mercury were generally measured in the FGD filtrate (liquid). Scrubber conditions that resulted in higher mercury levels in the scrubber filtrate by-product included operation at low $\mathrm{pH}$ and low $\mathrm{L} / \mathrm{G}$ and borderline slurry oxidation stoichiometries. The elevated levels of mercury detected in the absorber filtrate stemming from scrubber operation at low $\mathrm{L} / \mathrm{G}$, low $\mathrm{pH}$ and low oxidation stoichiometries should be verified.

A second FGD system was evaluated for mercury control. Total mercury control across a dry scrubber/ baghouse system was characterized for two Ohio coals. In spite of the varying levels of mercury and sulfur in the coals, comparable total mercury control between $60-65 \%$ was achieved.

\section{Coal Cleaning}

The contribution of coal cleaning towards the reduction of mercury emissions from coal-fired electric utility boilers was evaluated. About 75 to $80 \%$ of the bituminous coal consumed by the power generation industry is cleaned to some extent. The effect of coal washing on mercury and chlorine in both the coal and on boiler emissions was examined for three Ohio bituminous coals. The cleaned coals were slightly enriched in chlorine by the cleaning process, indicating that chlorine may be more concentrated in the bulk raw coal than in the ash fractions. Coal cleaning produced a significant decrease in mercury concentration for all three coals, with mercury reductions ranging from 36 to $47 \%$. As expected, sulfur also decreased as a result of cleaning for all three of the coals.

For the three Ohio coals evaluated, the reduction in mercury concentration in the coal from washing correlated to the percent reduction of ash. Based on these results, precombustion cleaning for mercury reduction in Ohio coals appears to be related to the efficiency of the ash removal in the cleaning process. The complexity of the commercial cleaning process or the extent of washing was not observed to have an effect on the mercury removal beyond the efficiency of the ash removal. The average reduction in mercury emissions from the boiler attributable to the commercial coal cleaning process was $49 \%$, and ranged between 45 to $56 \%$. Mercury emission reductions resulting from coal cleaning were higher than the mass removal in the coal as the increased coal heating value translates to a lower coal feed rate. 
Mercury species and emissions were tracked through the entire utility coal utilization process, including precombustion, combustion and post combustion processes for several Ohio coals. As indicated in Figure 9, the major reduction in mercury emissions resulted from coal cleaning and wet scrubber operation. The contribution of coal cleaning towards the abatement of mercury emissions relative to the raw coal source averaged $49 \%$. The conventionally operated baghouse and ESP effectively reduced the particulate-phase mercury but provided negligible control of the vapor-phase mercury emissions. When the wet scrubber was operated downstream of the baghouse, between 82 to $92 \%$ of the remaining vapor-phase mercury emissions were controlled for the three Ohio bituminous coals. Mercury control averaged 42 and 53\% for two Ohio coals when the wet scrubber was operated downstream of the ESP. As the majority of eastern and Midwestern bituminous coal shipments are already cleaned to meet customer specifications, wet scrubber technology may provide the best option towards the reduction of existing mercury emissions from utility stacks.

\section{Advanced Measurements}

Two advanced measurement techniques were evaluated for on-line or near on-line measurement of selected air toxics. Due to the current interest in mercury emissions and control from coal-fired boilers, continuous mercury analyzers were targeted. The performance capabilities of the Seefelder Messtechnik (SMT) mercury monitor system (supplied by EcoChem, West Hill, CA) were evaluated. Prior to evaluation under this program, operating experience for the total and elemental mercury analyzers was limited to facilities firing fuels other than coal. The AECDP evaluation of the SMT system presented operating and analytical difficulties due to the higher $\mathrm{SO}_{2}$ and lower mercury concentrations present in coal-fired flue gas. An on-line Fourier Transform Infrared Spectrometry

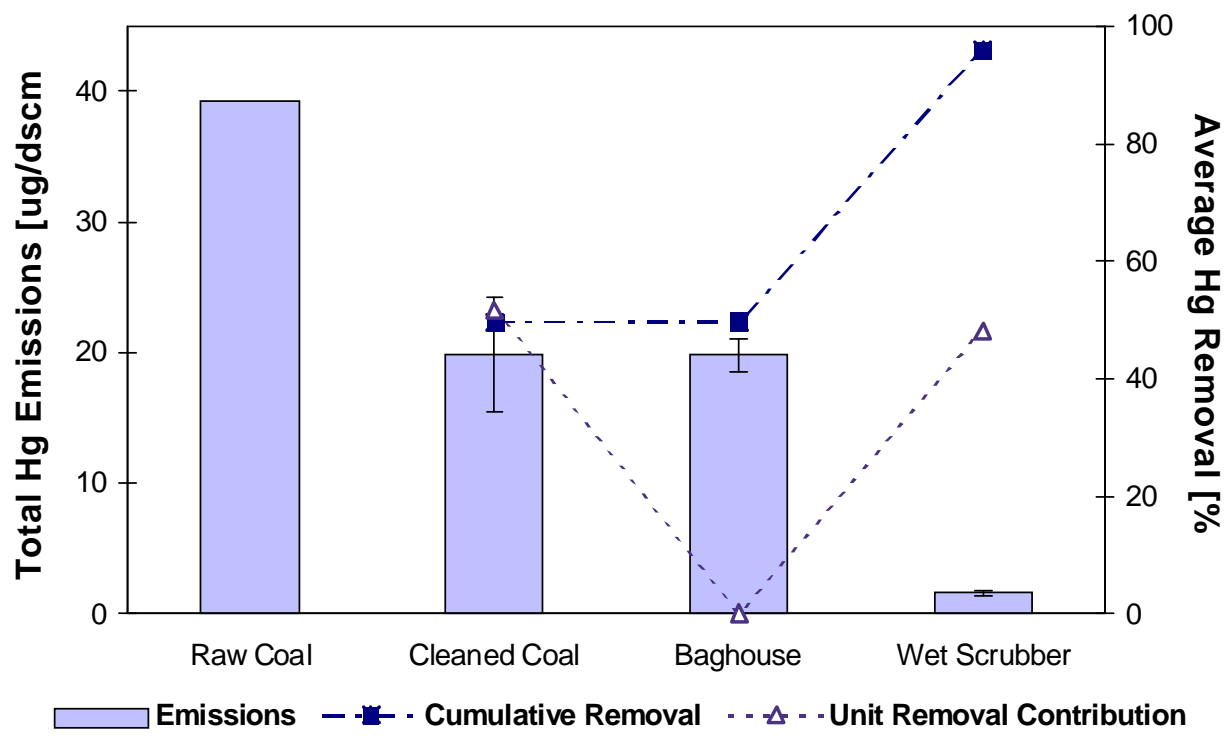

Figure 9 -- Mercury Emissions Reduction in a Utility Plant Equipped with a Baghouse Ohio 6A Coal 
(FTIR) analyzer was also evaluated for the ability to simultaneously monitor several flue gas components, especially hydrogen chloride.

The evaluation revealed that the mercury monitor was fairly robust. However, due to the extensive interference of $\mathrm{SO}_{2}$ even at the reduced levels downstream of the wet scrubber, the monitor system would not be applicable for the compliance to mercury standards for coal-fired power plants in its current configuration.

Although the FTIR has great capability for simultaneous concentration measurements of multiple gases, measurement is made more difficult by the presence of water vapor. The infrared spectra of water vapor overlaps, to some degree, the spectra of many of the flue gas components. One exception is $\mathrm{HCl}$. At the outlet of a wet scrubber, the water vapor concentrations are very high, so that measurements of some gases are not possible at that location. Most of the constituents of the flue gas that can be measured with the FTIR have very low solubilities in water, so that removing the water from the flue gas before the measurement is a solution. However, $\mathrm{HCl}$ is highly soluble in water and would be effectively removed. Therefore, it is difficult to monitor many flue gas components and $\mathrm{HCl}$ simultaneously with a FTIR. 


\section{Work Performed During Reporting Period}

\section{PHASE I}

The Phase I scope of work was previously completed.

\section{PHASE II}

The Phase II scope of work consists of six major tasks. Phase II work began under Task 1, Project Planning and Reporting, on February 29, 1996.

\section{Task 1 -- Project Planning and Management}

Routine air toxics cognizance activities continued in the reporting period. This work includes a literature survey, discussions with a variety of other air toxics investigators, and participation in various meetings, seminars and workshops. The Phase II Project Evaluation Report was approved by the DOE-FETC for continuation into Phase III of the program.

\section{Task 2 -- Capture of Air Toxics in Conventional Systems}

Activity under Task 2 has been completed.

\section{Task 3 -- Impacts of Coal Properties on Air Toxics Emissions}

The primary objective of the third and final test series of Phase II was to evaluate the sensitivity of air toxic emissions and pollution control device capture efficiency to changes in coal properties. Two Ohio coals, Meigs Creek 9 and Ohio 6A (Lower Freeport), were selected on the basis of chlorine content. The coal chlorine content is believed to impact the mercury speciation in the flue gas and therefore, affect the mercury control performance of conventional wet scrubbers. The contribution to mercury emissions reduction from cleaning the coal prior to combustion was characterized through chemical analysis of the raw and cleaned coal and the measurement of emissions from firing the cleaned coal.

The coal property tests were completed on schedule and budget. As a result, four Ohio bituminous coals containing a range of mercury and chlorine concentration have now been characterized for mercury emissions data and emissions control performance. Activity under Task 3 is complete.

\section{Task 4 -- Advanced Air Toxics Measurement Concepts}

The purpose of this task was to identify and/or develop advanced concepts for on-line or near on-line measurement of selected air toxics. Due to the current interest in mercury emissions and control from coal-fired boilers, this task targeted on-line mercury analyzers. Activity under this task is complete. 


\section{Task 5 -- Data Analysis and Reporting}

Preparation of the Phase II final report was completed. The draft report was distributed to the project sponsors and approval was received from the DOE. The required status reports were prepared and issued.

\section{Task 6 -- Technology Transfer}

A summary of the wet scrubber parametric test results were forwarded to the USEPA for consideration in the revision of the report, Study of Hazardous Air Pollutant Emissions from Electric Utility Steam Generating Units. The Interim Final Report contained a median mercury emissions control efficiency estimate of $17 \%$ for wet scrubbers on the basis of sampling at five commercial plants. Previous written communication from MTI questioned the assumptions made for the initial estimate. In addition to providing evidence of the much higher levels of mercury control that can be achieved by wet scrubbers, data on the impacts of commercial coal cleaning processes on mercury and chlorine contents in Ohio bituminous coal was provided to the USEPA. We have been told verbally by Martha Keating (USEPA) that the AECDP information will be considered for use in the revised report.

Two technical papers were completed. The first, "Control of Mercury in Conventional Flue Gas Emissions Control Systems" was prepared for the EPRI-DOE-EPA Managing Hazardous Air Pollutants Conference. The second, "Parametric Testing of FGD Mercury Control" was prepared for the POWERGEN International '97 Conference. 


\section{PHASE III - - ADVANCED CONCEPTS AND COMPARISON COALS}

The Phase III scope of work consists of six major tasks. Phase III work began under Task 1, Project Planning and Reporting, on September 1, 1997.

\section{Task 1 - - Project Planning and Management}

Work primarily consisted of planning and scheduling activities related to the preparation of the Phase III Management Plan (DOE) and Phase III Milestone Plan (OCDO). A Participants Committee meeting was held with the program sponsors to discuss both the results of Phase II work and plans for Phase III testing. Feedback on the project direction was positive. Arrangements are underway for the next meeting of the Advisory Committee as an initial milestone for Phase III. Routine air toxics cognizance activities were continued.

\section{Task 2 - - Advanced Control Concepts}

The objective of this task is to develop advanced air toxics emissions control concepts targeted at specific substances for which adequate control is not achieved with conventional flue gas cleanup systems. There was no activity under this task.

\section{Task 3 - - Comparison U.S. Coals}

The objective of this task is to evaluate the sensitivity of air toxics emissions and flue gas treatment device capture efficiency to changes in coal type and properties. There was no activity under this task.

\section{Task 4 - - Advanced Measurement Concepts}

As discussed during the Participants meeting, mercury monitor selection criteria will place greater emphasis on monitor capacity as a research tool than in the previous phase. There was no activity under this task.

\section{Task 5 - - Data Analysis and Reporting}

The objective of this task is to evaluate, correlate, and summarize the results of air toxics testing work performed during Phase III. There was no activity under this task.

\section{Task 6 - - Technology Transfer}

A member of the project team attended the Center for Air Toxic Metals Fourth Annual Meeting at the Energy \& Environmental Research Center (EERC) in North Dakota. 


\section{Planned Work for Next Reporting Period}

\section{PHASE II}

\section{Task 1 - - Project Planning and Management}

Routine air toxics cognizance activities will continue. The milestone plan will be issued to the project sponsors for review and approval. The next meeting of the Advisory Committee will be held in October at the Alliance Research Center.

\section{Task 2 - - Advanced Control Concepts}

Initial planning for testing under task 2 will begin. The first test series is currently planned for December.

\section{Task 3 - - Comparison U.S. Coals}

No activity is planned.

\section{Task 4 - - Advanced Measurement Concepts}

Selection of a continuous mercury monitor will begin.

\section{Task 5 - - Data Analysis and Reporting}

One of the primary objectives of the project is to develop a data library. Progress will be made in the next reporting period towards posting the data library on the internet. Required status reports will be issued.

\section{Task 6 - - Technology Transfer}

"Control of Mercury in Conventional Flue Gas Emissions Control Systems" will be presented at the EPRI-DOE-EPA Managing Hazardous Air Pollutants Conference to be held in Washington, DC in November. "Parametric Testing of FGD Mercury Control" will be presented at the POWER-GEN International '97 Conference in Dallas, Texas in December. The Newsletter will be issued. 
Advanced Emissions Control Development Program

\section{Phase II Milestones and Schedule}

Progress to date is illustrated in Figure 10. Completed milestones are indicated in the figure.

\section{Budget and Schedule Issues}

None. 


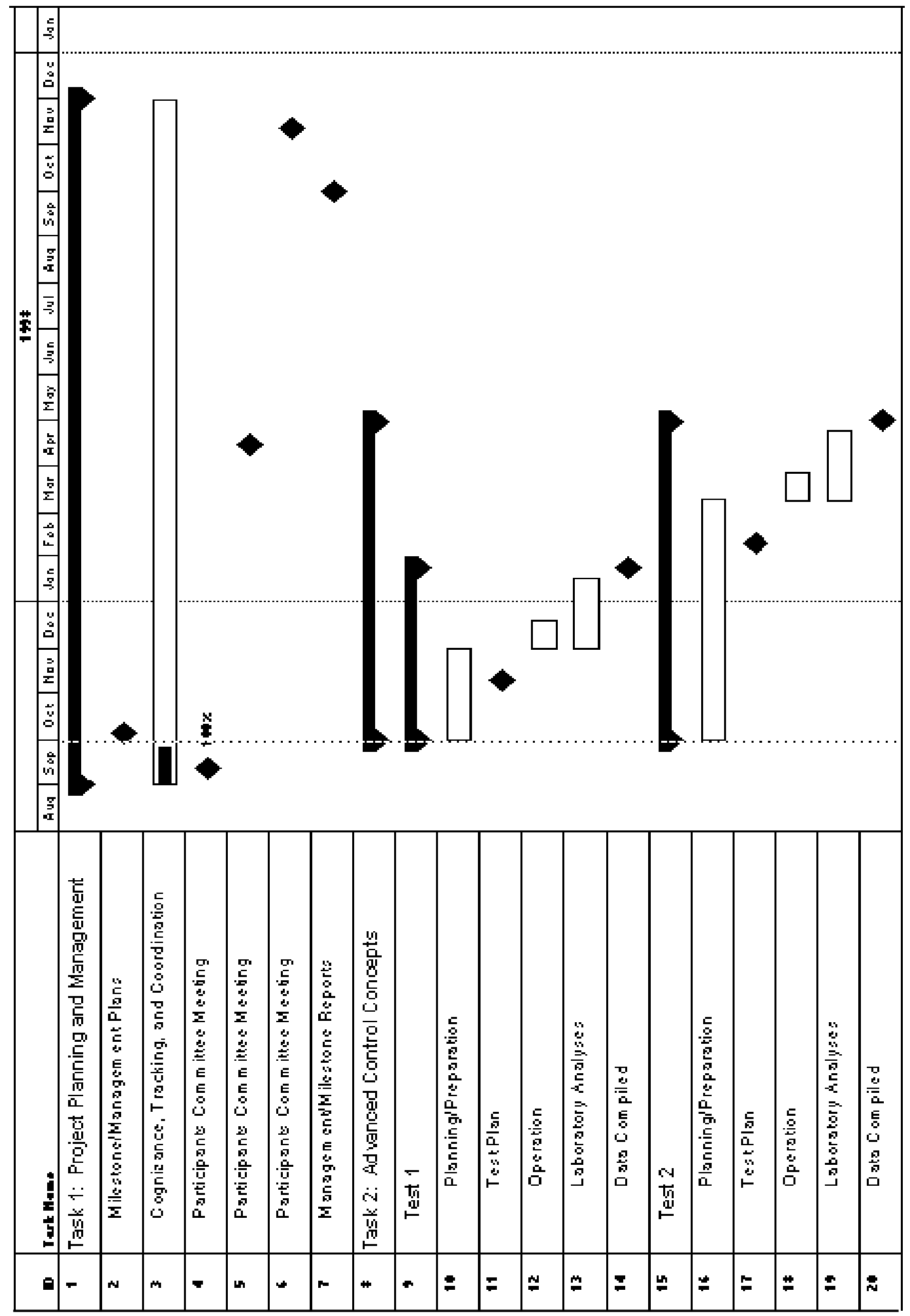

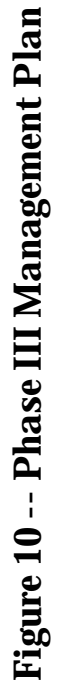




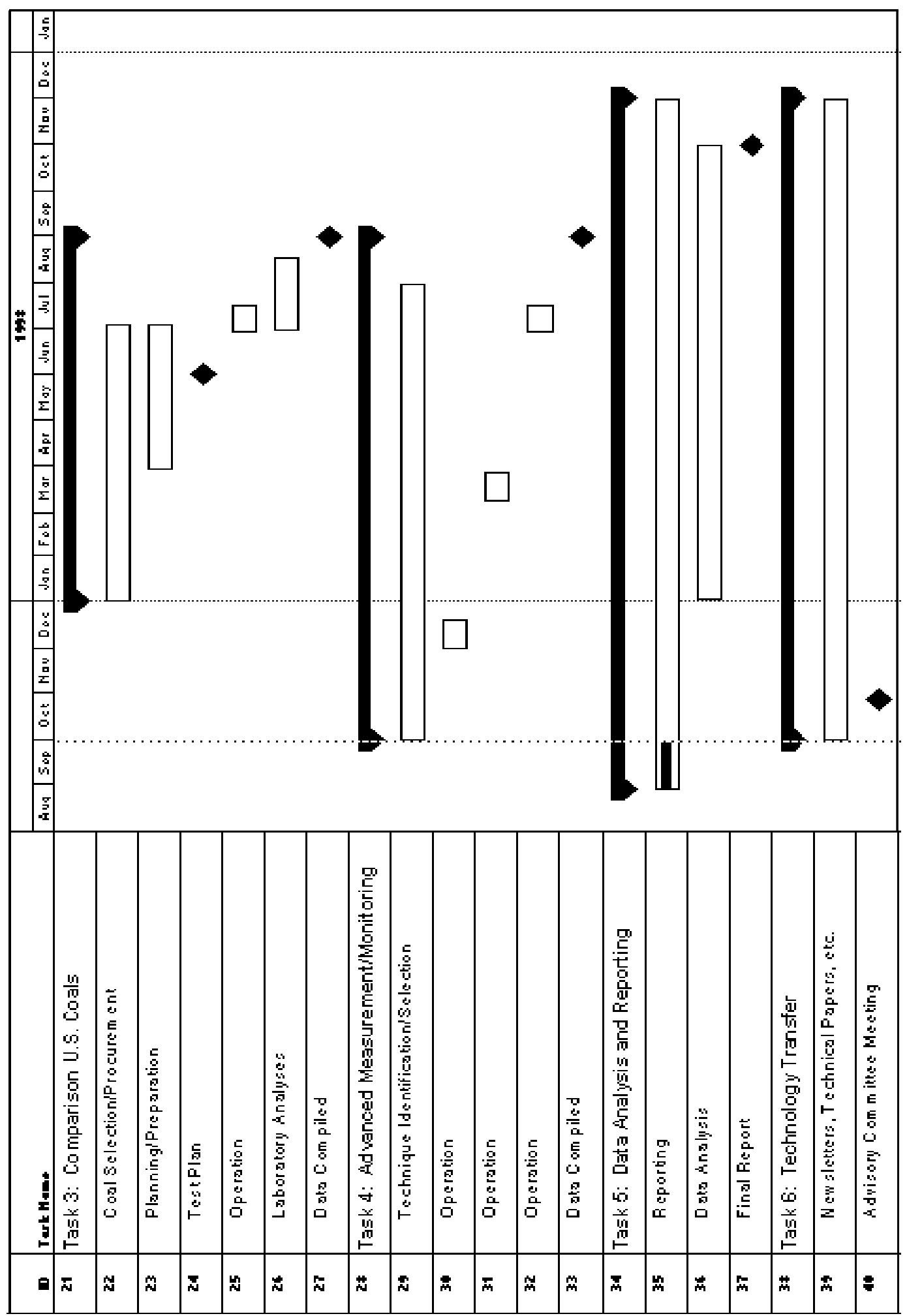

